Iranian Journal of Applied Linguistics (IJAL), Vol.18, No.1, March 2015, 127-166

\title{
An Activity Theory Analysis of ELT Reform in Iranian Public Schools
}

\section{Seyyed Ayatolla Razmjoo}

Associate professor of Applied Linguistics,

Shiraz University, Shiraz, Iran

Elyas Barabadi*

Ph. D Candidate in Applied Linguistics,

Shiraz University, Shiraz, Iran

Received 5 December 2014; revised 16 January 2015; accepted 15 February 2015

\begin{abstract}
The present study takes Engeström human activity system model $(1987,1999)$ as a theoretical framework to investigate the CLT-based English curriculum reform in Iran which was initiated in 2013 by the Ministry of Education in public schools.
\end{abstract}

E-mail address: elyas.ba1364@gmail.com

Corresponding address: Department of Foreign Languages and Linguistics, Shiraz University, Eram square, PO box 7194685115 
With the premise that human activity is artifact-mediated and goal-directed, activity theory makes it possible to demonstrate the complex and dynamic relationship between various institutional, social, and individual factors by revealing different contradictions that language teachers would experience as they attempt to implement CLT in their classroom contexts. In addition to 23 language teachers who consisted the main participants of this study, three other groups including 17 teacher directors, 23 students, and 20 parents took part. Document analysis, semi-structured interview, and classroom observation comprised the data collection instruments. The results indicated that despite their optimism about and keen interest in CLT-based reform, Iranian language teachers could not successfully implement CLT due to their inability to successfully resolve the contradictions that emerged in their activity system. These contradictions in turn stemmed from a number of difficulties that emanate from various sources including teachers themselves, students, their parents, school staff, educational system, and the new package. Based on the findings, a number of implications and suggestions are provided for the Iranian curriculum developers, language teachers, parents, and teacher directors.

Keywords: CLT-based curriculum; Activity theory; Contradictions; Grounded theory approach

\section{Introduction}

Over recent years, education systems have undergone rapid and multiple changes in many parts of the world (Craft, 2000). Yet, Iranian students have been provided with the same monotonous English education as the same structure-oriented English textbooks based on grammar-translation and audio-lingual methods have been used for 27 years (Alavi, 2013). Fortunately, since 2013, the Ministry of Education has initiated some changes in English education with the introduction of new textbooks which advocate a communicative approach to English teaching. With the introduction of a new curriculum, a lot of changes either occur such as those in the textbooks, or are expected to occur such as those in teachers' 
instructional practices and perceptions to the new curricular changes. The former types of changes are not difficult to notice, whereas the latter types call for a careful and critical scrutiny. As such, and given the historical background of English education in Iran, the current study aims at examining how English teachers perceive the new English curriculum and the extent to which they are capable of putting it into practice. The present study takes Engeström's (1987, 1999) human activity system as the theoretical framework for examining teachers' perceptions and practices within the particular social and institutional context of English Education in Iran. Activity theory proposes that human cognition cannot be considered as an individual phenomenon which lies only within persons as individual; rather, it is socially constructed and developed (Cole \& Engeström, 1995). To the best of the researchers' knowledge, to date, no study has examined the implementation of the new English curriculum in Iran from an activity theory perspective. The study can be informative by providing guidance as how to apply CLT-based curriculum more effectively in our EFL context. In fact, our local practitioners in the socio-cultural context of Iran are in need of less abstract and more practical guidance appropriate to their local context.

\section{Objectives of the Study and Research Questions}

According to Larsen-Freeman (1983), the teachers' lack of awareness on the one hand, and their own attitudes on the other hand might prevent them from adopting and following new policies and curricular innovations. Moreover, teachers' active involvement in the classroom might lead them to select certain aspects of the curriculum and ignore other aspects which might seem useless in their views as a result of their long-period teaching and learning observation or what Lortie (2002) calls "apprenticeship of observation." Thus, research into this area can be beneficial in two ways: First, it can reveal how teachers understand curricular innovation and put it into practice. Second, it has the potential to help teachers, teacher educators, and even policy makers implement the new curriculum more effectively by bringing all potential contradictions to the surface. Specifically, this study aims to answer the following two questions: 
1. How do Iranian English teachers in junior high schools perceive and enact the new CLT-based curriculum?

2. From an activity theory perspective, what contradictions might emerge in Iranian language teachers' instruction as a result of new curricular changes?

\section{Review of the Related Literature}

Recently, different aspects of curricular reform have been studied by different researchers (Carless, 2001; Fullan, 2000; Markee, 1997, 1994). Since curricular innovation is a very complicated process, each researcher has focused on one particular aspect of it. For example, researchers such as Calderhead (2001) and Cooper (1989) have studied motivation for curricular innovation. Other researchers (Fullan, 1998; Markee, 1994) examined the successful implementation of curricular reform. In this study, first, the studies that focus on the role of teachers in the implementation of CLT-based curricular reform in EFL contexts are reported. Then, Engeström's $(1987,1993,1999)$ human activity system model which acts as the analytical basis of the study is presented.

\section{The impact of CLT-based curricular reform on classroom instruction}

Many researchers have investigated the effect of CLT-based curricular reform on teachers' instructional practices. Some of these researchers (Carless, 2001; Harrison, 1996) have dealt with how curricular reforms were implemented by teachers. That is, how teachers' instructional practices were influenced by such reforms. Other researchers such as Choi (2000), Kim (2002), and Li (1998) have investigated this issue based on teachers' self-report.

Using observation as her main data collection tool, Karavas-Doukas (1995) investigated the impact of CLT-based curricular reform on teacher's classroom practices in Greek secondary schools. The results of her study indicated that teachers were the only authorities in the classrooms as they transmitted knowledge and evaluated student's language in a traditional way. She concluded that since 
both teachers and students had been socialized into traditional teacher-centered instruction with a focus on grammar and translation instead of oral skills and communication, both parties contributed to the unsuccessful implementation of CLT-based reform.

In Hon Kong, Carless (2001) conducted a case study with an individual teacher who could successfully implement task-based curricular reform in her classroom. Using an attitude scale, classroom observation, and interview with the teacher, Carless (2001) came to this conclusion that this teacher could successfully adapt her instructional practices to the requirements of the new curriculum. The researcher attributed the successful implementation of the new curriculum by the teacher to her positive attitudes toward the new curriculum.

Using human activity theory as envisioned by Engeström (1987, 1993), Kim (2008) investigated the implementation of curricular innovation in the context of Korean secondary school. The CLT-based reform focused on communicative activities and tasks as well as the use of English as the medium of instruction. Using classroom observation, interview, and stimulated recall interview, Kim (2008) collected data about two participating teachers' instructional practices and perceptions and came to the conclusion that they could not teach English language communicatively as envisioned by the Ministry of Education due to a number of factors, namely their adherence to traditional methods of teaching such as choral reading and grammar explanation, their traditional beliefs about language learning and teaching, and their own learning experiences as language learners.

In sum, extensive research in different parts of the world (Choi , 2000; Carless, 2001; Kim, 2002; Kim, 2008; Wang, 2006 ) indicates that English teachers' beliefs and instructional practices are not in line with the principles of CLT as proposed by the policy makers in a top-down manner. Overall, six major factors were underpinning the discrepancies between the principles of mandated curricular reform and the teachers' practices: 1) teachers' belief systems, 2) students' belief systems, 3) institutional constraints, 4) lack of professional development 
opportunities, 5) lack of understanding of the CLT principles as proposed by policy makers, and 6) lack of social and cultural support, such as parental involvement.

\section{Theoretical framework}

According to Lantolf (2000), the cultural-historical activity theory was an effort by Vygotsky (1987) and Leont'ev (1981) to develop a new psychology which was different from psychoanalysis and behaviorism by emphasizing the artifactmediated and object-oriented action. Tools and artifacts are of paramount importance in activity theory since they shape the way human beings interact with reality. The basic unit of analysis in activity theory is human activity which tends to be mediated by a set of instruments or tools (Lantolf, 2000). Interpreting Leont'ev's (1978) formulation of activity theory, Lantolf (2000) points out that activity is doing something which is motivated by a biological or culturally constructed need. Lantolf (2000) identifies three levels for any activity as proposed by Leont'ev (1978). These levels are the level of motivation, the level of action, and the level of conditions. It is worth noting that since only the level of conditions is observable, it is not possible to neatly map a specific activity onto a specific goal or motive.

\section{Engeström (1987) model of a collective human activity system}

Engeström (1987) believes that human activity system is composed of a number of components, which are in constant and dynamic interplay with one another. His human activity system model indicates how individual activities are interwoven with other individual activities and where individual thinking emerges in context. In an effort to frame various participants and processes and their relationships within a particular system like English education, Engeström (1987) proposed a model of a collective human activity system as follows: 


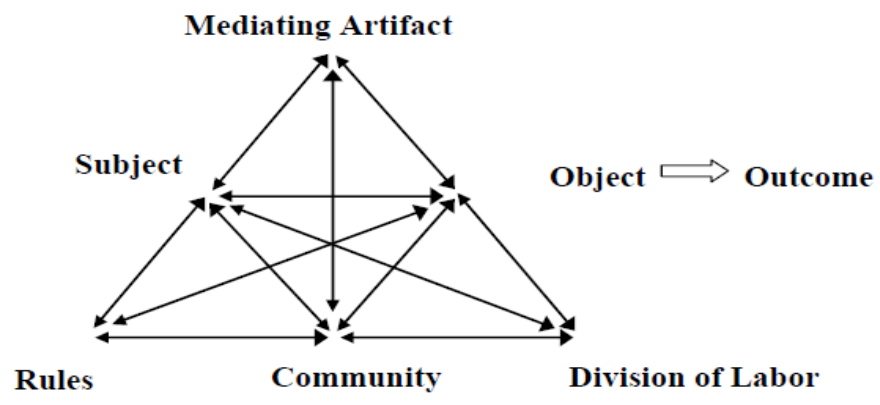

Figure 1

The structure of Human Activity System. Adapted from Learning by expanding: an activity-theoretical approach to developmental research (Engeström, 1987, p. 78).

In an activity system, the subject refers to the individual or sub-group whose agency is the focus of the analysis. For example, in the context of the current study, understanding how an Iranian English teacher understands, functions, and engages in a certain goal-directed activity like the enactment of CLT-based curriculum is the focus of the study. The object indicates the orientation of the activity at which the activity is directed. It is worth noting that the object does not have a stable character since it is continuously molded and transformed into an outcome under the influence of a set of mediating artifacts. For example, if development of students' communicative proficiency is the object of instruction, but students are concerned with a grammar-based exam, they cannot pay full attention to the object of instruction (that is, communicative proficiency) due to the mediating effect of the grammar-based exam as an artifact. In such a case, the object will transform into an outcome.

The three components of the activity system at the bottom of the diagram including, community, rule, and division of labor integrate the local human activity and the larger social, cultural, and historical structures. Community refers to a group of people who are concerned with the same object. For example, Iranian English teachers who try to improve secondary school students' communicative proficiency in a specific school comprise the community. Division of labor is 
concerned with both horizontal and vertical division of tasks and authority. According to Johnson (2009), rules refer to "both explicit and implicit norms and conventions that place certain limits as well as possibilities on the nature of interaction within the activity system" (p.79). Activity system is particularly linked to socio-cultural theory in that every dimension of the activity system, such as subjects' personal histories as well as the norms and values of community, results from its socio-cultural history.

The multi-directional arrows in Engeström's (1987) model indicate that each component in the activity system is closely interconnected with other components either directly or indirectly. Holding the belief that a phenomenon should be investigated in an integrative way, Engeström (1999) proposed the situated activity system as the unit of analysis. Taking the situated activity system in its entirety as the unit of analysis helped Engeström (1999) overcome two limitations associated with other research methods studying human cognition and behavior. First, by taking into account different components within the activity system in an integrated way, activity theory does not ignore the broader context in which the subject is situated. Second, the very agency of human beings as the subjects of the activity system is taken into account by recognizing their constructive role in both forming and transforming the context and the activity system as a whole.

\section{Inner contradictions and interventions}

Engeström (1987) defines "inner contradiction" as the clash between individual actions and the total activity system (p.39). The notion of inner contradictions is particularly important in activity theory in that it reveals the unstable nature of activities (Engeström, 1987, p. 7). Engeström (1987) proposes four levels of contradictions: primary, secondary, tertiary, and quaternary; of which, only secondary and quaternary contradictions are explained in details since the former are the moving force behind advancing any activity system, and the latter are responsible for producing the subjects of central activity system. According to Engeström (1993), secondary contradictions which occur between one component of the activity system and other components are fundamental to understanding a specific activity system since they are responsible for the change and development 
in the system. Indeed, it is through the resolution of such contradictions that the activity system can be transformed into a new quality. This type of contradictions usually occurs when "a strong novel factor" is introduced into any component of the activity system. It is the introduction of the novel factor that instigates the disturbances and innovations within the activity system. If the new English curriculum causes secondary contradictions in English teachers' activity system, and if teachers attempt to resolve such contradictions, real changes in teacher instructional activity systems are expected. Otherwise, the educational reform does not go beyond superficial changes in which the same old practices might be used with some changes only in some names and terms.

Quaternary contradictions arise when there is conflict and dissonance between a central activity system (e.g. instructional activity system in which Iranian language teachers are subjects) and its neighbor activities (Engeström, 1987, p. 103). Activity systems, such as teachers colleges in Iran (or, teachertraining centers), universities, and in-service teacher- training programs which are responsible for producing and training the subjects of the central activity system are considered as neighbor activities.

\section{Participants}

\section{Method}

Four groups of participants contributed to this study. The major group of participants consisted of 23 language teachers (13 females and 10 males) teaching English in the seventh and eighth grades. All participating teachers had received their primary and secondary schooling in Iranian public schools. 20 teachers had BA and three of them had MA in TEFL. For most participating teachers, teaching experiences were limited only to secondary schools where they had been teaching English through traditional methods. The second major group was comprised of 17 teacher directors (11 males and 6 females) who had participated in Tehran inservice programs in 2013 and 2014. Nine teacher directors had MA in TEFL, six had BA, and there were two PhD students among them. In addition to these two groups, 23 students as well as 20 parents took part in the study. 
Since there were four groups of participants, the researchers had to use several variations of purposive sampling including maximum variation sampling, criterion sampling, and convenience sampling. Beginning with teachers and teacher directors, maximum variation sampling was used in order to include participants who could increase the differences on certain characteristics such as gender, teaching experience, and different workplaces (i.e. urban, rural and inner-city schools) that were likely to influence the enactment of the new curriculum as indicated by some researchers (Kim, 2008; Wang, 2006). Criterion sampling was used to select one top student from each participating teacher's class. These students who according to their teachers had an active participation in classroom activities were more likely to provide helpful information regarding their teachers' instructional practices. Ultimately, the researchers took 20 volunteer parents to be interviewed about their expectations from language teachers, their children, and English education in public schools in general. In order to preserve the anonymity of the participants, pseudonyms were used for all participants throughout the study.

\section{Instruments}

The use of various data maximizes the chance of obtaining trustworthy and credible findings (Lincoln \& Guba, 1985). Accordingly, different instruments were used to collect various data in order to answer the research questions: curriculum documents, interview, focus group interview, and classroom observation.

\section{Documents}

Documents of various types such as files, reports, memoranda, and minutes can be used in qualitative research in order to understand the phenomenon under study (Ary, Jacobs, \& Sorenson, 2010). The documents used in this study included a manual in which CLT was introduced, some official documents related to language testing (test specifications for seventh and eighth-grade EFL students, and the communicative language assessment), the newly designed English language textbooks, student's workbook, teacher's guide, televised interviews with authors of the new textbooks and other related materials. All these documents are available 
on the official website related to the new English curriculum with the following URL: http://eng-dept.talif.sch.ir/index.php. Additionally, a sample of mid-term and final exams constructed or at least used by language teachers was analyzed in order to see whether students' evaluation was based on the CLT-based curriculum or not.

\section{Interview and focus group interview}

Applying grounded theory approach for data analysis, the present study used interview and focus group interview (Ary, et al, 2010) as the main data collection methods. The first semi-structured interview scheme was developed based on the analysis of various documents in order to see to what extent the authors' conceptualizations of CLT and its implementation matched those of teacher directors who acted as mediators between authors of the new textbook and English teachers. The insights gained through interviews with teacher directors let the researchers design semi-structured interviews with language teachers and the students. Ultimately, another semi-structured interview was used in order to figure out the parents' views towards the new textbooks, their expectations from language teachers as well as their own children, and the kind of cooperation and support they could provide for their children.

\section{Classroom observation}

Classroom observation was also used in order to better understand language teachers' perceptions and their enactment of the new curriculum with the focus of observation being on teachers' instructional practices, students' behavior, and their involvement in different classroom activities. To this aim, an observation checklist presenting a list of CLT features as envisioned in the new curriculum was developed. The researchers then checked whether these features were present or absent in participating teachers' instructional practices. It should be noted that conducting any research within Iranian schools requires the official permission from the authorities in Educational Organization. In some cases, the officials said that the research could be conducted only through distributing questionnaire, and that language teachers and the students should not be disturbed by the researchers' presence. Having gone through the cumbersome bureaucracy, the researchers were allowed to observe one lesson (taking at least four sessions to be taught) from each 
participating teacher. Aside from administrative problems, the educational culture where Iranian teachers work does not hold positive attitudes towards observation, and it is usually regarded as a threat. Ary et al (2010) also viewed the intrusive nature of observation as the main drawback of this data collection instrument. In case of female schools and female teachers, it was much harder to get official permission and seek teachers' cooperation and consent. Given these personal and cultural concerns on the one hand, and ethical issues on the other hand, the researchers decided on the observation of only one lesson.

\section{Data collection procedure}

Except for 10 teacher directors and eight language teachers who were interviewed through focus group, the rest of the participants from all four groups were interviewed individually and the discussions were audio-recorded for further transcription and analysis. Except for three interviews, the rest was conducted in Persian since most of the participants felt more comfortable and the interviews would be less time-consuming. However, there was no time limit for the interviews ranging from 10 minutes in case of parents and students to one and half an hour in length in case of focus group interviews with language teachers and teacher directors. The interviews began with teacher directors who had attended the inservice program in Tehran. The insights obtained through these interviews and the analysis of various documents helped the researchers design and conduct interviews with other groups. The interviews with language teachers were initiated with a brief introduction to CLT-based curriculum. Then, the interviewees were asked to concentrate on different components of the new package, their own instructional practices, and the relationships of these two to other components of the human activity system in this study. Having conducted the interviews and established rapport with teachers, the researchers began the observations. Attempt was made to observe one complete lesson taught by each participating teacher. In addition to taking notes, the lessons were audio-recorded for further analysis and interpretation. After interviewing the teachers, one student from each class was interviewed in order to compare the teachers' assertions concerning their 
instructional practices with those of their students. Ultimately, 20 parents were interviewed to examine their viewpoints about the new textbooks as well as their expectations from their children and language teachers.

\section{Data analysis procedure}

Immediately upon conducting the first few interviews with each group of participants and taking notes from each class, the coding process began. The transcribed data were coded using open coding in which the researchers meticulously and repeatedly read and considered every comment made by each participant in order to find out similarities and differences between various concepts. At this initial stage, almost the entire transcriptions were coded since the researchers did not know in advance what pieces of data were or were not relevant to the emerging theory. At this stage of data analysis, a wide range of concepts and categories were identified. These initial concepts and categories were about various aspects of CLT-based curriculum reform ranging from personal and professional factors to more broader social, institutional, and cultural factors. Then, using axial coding, the researchers tried to develop the main categories explaining and accounting for the maximum load of the concepts and categories detected at the first stage of data analysis. In the third step, some of these core categories were integrated into four major factors influencing Iranian language teachers' conceptualization and implementation of the new English curriculum. The resulted concepts and categories obtained through each set of interviews and classroom observation helped the researchers reformulate interview questions continuously in order move towards the new and more focused direction of the research. Ultimately, drawing on Engeström human activity system model (1987), the present study could develop a model accounting for various contradictions that emerged in the current activity system (see Figure 2).

\section{Results}

Developing a grounded theory on the basis of activity theory as done in this study might seem problematic since the former has been traditionally viewed as a solely positivist approach rejecting contributions from any existing theory. Indeed, the theory should only emerge from the data in an inductive way. Thus, the first 
section tries to explain how a grounded theory of activity can be justified. Then, the themes extracted from various types of data are discussed under four categories. These categories depict how Iranian language teachers conceptualize and implement the new English curriculum in their local contexts. Finally, drawing on the findings discussed in section two, the last section tries to provide an activity theory explanation of English education in Iranian secondary school in light of the principles of the new English curriculum by presenting a model accounting for various contradictions.

\section{Grounded theory vs. Activity theory}

At first glance, grounded theory and activity theory seem to be conflicting methodologies since the former with its positivist underpinnings (Seaman, 2008) aims at inductively developing a theory about the problem at hand by gathering data about participants' experiences in a particular context (Ary et al, 2010), while the latter takes the influence of context and socio-cultural forces as granted (Lantolf, 2000). In contrast to this pure positivist view of grounded theory (discovery perspective), Strauss and Corbin (1998) introduced the construction view of grounded theory in which an existing theory (e.g. activity theory or any other theory for that matter) might be utilized as part of the analysis. Taking this stance towards grounded theory, Seaman (2008) views grounded theory as a flexible approach and not a strict methodology which would be susceptible to "ontological ambivalence", i.e. a drawback of traditional grounded theory research in which exclusive reliance on the data for developing a theory might compromise the chance of finding out the effect of context on participants' actions. Seaman argues that there are not enough clues within data gathered in grounded theory as to the effect of context. Accordingly, some cultural concepts need to be imported from an existing theory to "open up context-analytic possibilities" (p. 4) for grounded theory. For Seaman, this existing theory is activity theory since despite its ontological differences with grounded theory, it can be complementary by offering "clear strategies for substantively analyzing how social situations are constituted by culture" (p. 5). On the other hand, grounded theory can benefit activity theory by offering systematic methods for collecting, managing, and 
interpreting data. The result of this synthesis is what Seaman (2008) calls "constructing a grounded theory of activity" (p. 13). What follows is a description of different elements of this eclectic research method:

To begin with, taking activity as the unit of analysis helps the researchers expand the scope of inquiry beyond observation, talk, and interview data. Activity as the unit of analysis makes it possible to take into account the broader social, cultural, and historical forces like norms of society, community and its members, overall objective of the activity, and various artifacts. In fact, various components of activity system can be used as data sources rather than as pre-given conceptual categories. For example, the norms or rules stand for one component that can be flagged as one important force or element within the activity system to be taken into account when collecting, managing, and interpreting data through grounded theory procedures. In other words, by specifying different elements of an activity system, activity theory provides the researcher with the overall social, cultural, and historical sources, while grounded theory lets the researcher be receptive to participants' own responses and meanings to understand the nature of these forces (Seaman, 2008). In the current study, for example, attempt was made to understand the norms of classroom participation to see whether teachers and students would take up their traditional roles in the new CLT-based class or not.

Moreover, activity as the unit of analysis enables the researcher to have a developmental analysis by examining the inner contradictions and their possible resolutions. Every activity system (English education in Iranian public school) has the same internal structure in which "changes in the organization of internal elements of [activity] are thought to occur when contradictions arise because old tools are put into new uses" (Seaman, 2008. p. 8). In the context of this study, old tools refer to the language textbooks, language activities, and the use of mother tongue instead of English in the class. The new uses can refer to the re-orientation of all these old tools towards the development of communicative competence as the new object of the activity system. Activity theory tries to steer the focus of analysis towards the object of the activity system to make sure whether various components of the activity system and the contradictions within them (or probable resolution of 
these contradictions) lead to the achievement of the new object of the activity system or not.

According to Seaman (2008), although activity theory does not have specific strategies for data collection and analysis, it can offer useful guidance on "recognizing incidents of tension and change" (p. 10) by anticipating the potential inner contradictions within activity system. It is this anticipation of contradictions that guides the researcher on how to structure the interview questions or what incidents of the classroom to choose as the focus of observation in such a way to understand "the key points of transition during the activity under study" (p. 10). Additionally, activity theory can inform the sampling of the study. As mentioned before, the primary goal of activity theory is to identify the points of tension and change (e.g. inner contradictions) that are necessary for development of activity system. This calls for shifting the sampling emphasis to unexpected directions. In other words, in order to identify these contradictions, the researcher needs multiple perspectives on various components of the activity system. In the context of the current study, recruiting four groups of participants and using maximum variation sampling for selecting the teachers and teacher directors (two main groups of participants) served this very purpose.

\section{Grounded theory results}

Optimistic about the New English curriculum yet incapable of its full implementation

Although the Iranian language teachers believed that communicative activities were necessary for stimulating the students' engagement and use of English, they did not make judicious use of them in their instruction and relied more on traditional repetition and translation activities instead. For example, while teaching the practice section of lesson eight of the textbook for the seventh-grade students, the teacher simply used the typical method of translating, reading aloud, and asking students to repeat after him (Field note, Apr 14, 2014). However, interviews with the same teacher clearly showed the contradiction between his attitude towards 
communicative activities and his actual practices. In this regard, Ahmad, one of the participating teachers, remarks:

\section{I think CLT method is more appealing to students than other methods and techniques such as translation and memorization of some texts. Well, the students want to learn well with CLT, and certainly they will learn better since they will get involved in various (communicative) activities.}

Despite being aware of and optimistic about the advantages of using appropriate instructional activities, most language teachers simply used traditional activities in their instruction in order to cover the content of the textbook. Classroom observation of participating teachers indicated that they tended to deal with various sections of each lesson in the following ways:

First conversation: Playing the audio file of the of the conversation and reading it aloud as well as providing the Persian translation line by line (Field Note, Nov. 15, 2014)

In response to the question that how their teacher taught the first conversation of each lesson, Habib, one eighth-grade student, said:

Our teacher usually writes a summary of the lesson on the board and makes us repeat the sentences after him. Then, he asks us to read the conversations aloud several times, and write it several times as our homework for the next session

Practices: Reading aloud by giving their Persian translation and asking students simply to ask and answer the turns in practices section (Field Note, Nov, 20, 2014)

Conversation 2: Most teachers simply skipped this conversation by only focusing on teaching the new alphabet letters in each lesson. At best, teachers tried to read it aloud and give the Persian translation of it (Field Note, June, 2, 2014). 
Closely related to the use of communicative activities is the students' use of English in the classroom. Language teachers' failure to set up and use communicative activities brought about tensions in their instruction (Field note, Apr 8, 2014). More specifically, this tension was created between their awareness of the benefit of creating opportunities for their students' L2 use through communicative activities on the one hand, and some institutional constraints such as their own lack of proficiency, the norms of the students' language use and classroom participation, and time pressure to cover the textbook on the other hand. Complaining about her own lack of proficiency as a language teacher, Mina observes:

I think our colleagues are inert now. They don't utter even a single sentence in English. I myself have dropped back (my speaking ability). I have many things in my mind that I cannot speak about them.

While this interview excerpt ascribes the limited use of English to teachers' low proficiency in spoken English, other teachers believed that lack of enough time on school schedule was the main cause. Regarding this, Saeed says:

During the second conversation, I was only worried about students learning the alphabet. In some lessons, I did not work on the conversation at all. What did matter for me was to introduce the new letters and their corresponding sounds. If I wanted to spend time on teaching "talk to your teacher" section of the second conversation, I would not be left with enough time to teach the alphabet.

Another point worth mentioning is related to the students' passive participation in classroom activities. Despite the teachers' agreement with the CLT principle that instruction should be learner-centered, they could not put it into practice. Regarding this, Maryam contends: 
You know, I'm afraid that students' mistakes are not corrected while talking to their friends, and they will learn English erroneously. So, I try to ask each student individually to monitor their production and correct their mistakes indirectly.

In this excerpt, the teacher's main fear was that students' errors would be fossilized when they talked among themselves. Hence, she preferred to take charge of asking questions and getting feedback from her students in order to take care of the mistakes that would have gone unnoticed if the teacher were not directly involved. Accordingly, language teachers were keen to emphasize accuracy when their students got involved in limited oral activities conducted in the classroom (Field Note, May. 13, 2014). Rather than encouraging the students to speak English and get their messages across, the teachers hastily and frequently interrupted the students who made some pronunciation mistakes in mid-sentence. Moreover, the students were not encouraged to use language freely. For example, students were not allowed to talk about their own favorite food and drink. Rather, they had to choose only the words provided in the practice section (Field Note, May, 16, 2014)

Some teachers, however, had to use more teacher-fronted instruction in order to increase the pace of instruction so that they could cover the content of the specified syllabus in due time. Still, as noted in excerpt below, some other teachers had to use more teacher-fronted instruction because they did not have the necessary equipments such as computer, data transparency, as well as some multi-media materials. According to these teachers, it is too ideal to expect teachers to run a learner-centered classroom where there is only a blackboard. More specifically, Ali, a language teacher in a village complained:

I could not use animations and songs more than a few sessions because I did not have access to computer and data projector. Imagine that I could not use the room that was 
equipped with data projector more than four sessions. I had to take my cell phone to class and this is not very suitable.

One of the recurring themes derived from the teachers' interviews was related to teachers' limited oral proficiency. Many English teachers acknowledged that the teachers' lack of general English proficiency especially spoken English was a big issue of English education. One teacher, Muhammad, for example, notes that:

I think since we English teachers ourselves are not proficient in English and conversation, we cannot be quite successful. This is the most important reason; since we graduated, we did not study English. There are very few teachers who want to study or need a book or even a newspaper, let alone to study English.

That teachers should be competent in spoken English in a CLT-based classroom is self-explanatory. Until teachers themselves are not capable of using the target language with ease, it is not reasonable to expect them to help their students acquire the speaking ability. In almost all models and frameworks of teacher education, knowledge of the target language including the ability to use that language fluently is an essential component of teacher knowledge base.

\section{Affective factors related to both language teachers and learners}

The grounded data analysis indicated that even language teachers who had high English proficiency and were well-aware of the principles of CLT were lacking in self-confidence when it came to actual implementation of the new English curriculum. When asked why there is some resistance even by those teachers who have good command of English, they expressed their uncertainty about the new method. Vahid, a language teacher with long teaching experience states: 
They (language teachers) are afraid that the students may not learn using the new method (CLT). Besides, they cannot generate the motivation among learners.

Another affective factor touching both language teachers and students was related to the new package itself. Although English teachers had a very positive attitude towards the new textbook and package which aimed at fostering learners' communicative ability, they believed that it has some shortcomings that do not allow both teachers and students to be as communicative as possible in the classroom. During a focus group interview, Ehsan, a teacher director explains:

The most acute one (shortcoming) is that it has taken very bold steps in developing communicative competence; Well, students are bombarded with so many words, grammar and functions especially in the final lessons that the teacher as well as the students do not know what to do and where to begin.

Similarly, parents voiced their concerns about the difficulty of the new textbooks given the allocated time on school schedule. For example, Bardiya's mother explains it in the following way:

I think if students were presented with English since their primary school and little by little, it would be more effective, instead of presenting a heavy load at once. Anyway, it (English) is a foreign language. In my opinion, it is overwhelming for the beginning (language learners); it is better to start with a lighter load and at an earlier age.

Still, another affective issue was related to the classroom management. Under the new English curriculum in which interaction between the teacher and students 
on the one hand and among the students on the other hand is necessary, management became an issue for English teachers. In this regard, Majid, a language teacher in an inner-city school observes:

Well, I think teachers are afraid they cannot manage the classroom as before. They are afraid of creating a mess if they allow learners to be active in the classroom. In my own classroom whenever I wanted to let the students work in pair or groups, I lost control of them, and they began chatting in Persian instead of English.

As can be observed in this except, the end result of pair work and group work which is an essential feature of a CLT-based classroom is to maximize the use of the target language among learners. However, the fear of losing control of the class discouraged the teacher to use pair work or group work in an appropriate way.

\section{Lack of favorable opportunities for teachers' professional development}

One recurring theme in data collected through interviews with teachers and teacher directors was related to lack of opportunities for language teachers' professional development. Some language teachers stated that they did not know various techniques and procedures to improve their professional development. Fariba, a language teacher who had just graduated from teachers college comments:

Well I think we teachers need continual support, sort of professional support. I think there should be an expert in educational department who can provide us with such support, who can observe our classes regularly not to pass judgment but to provide us with real and professional help. 
Another case in point is teacher supervision. According to many language teachers and teacher directors, the kind of supervision practiced in English classrooms is far from being facilitative. This point is clearly illustrated by the following interview excerpt taken from a focus group interview:

The fact of the matter is that the observation conducted by instructional groups is more formal (e.g. to comply with the legal requirement). The observers and other employees from educational department come (to school) and only fill out some forms. What I personally need is to be observed by an expert during the academic year.

Another related point concerning teachers' professional development is the in-service programs since they constitute the principal source of knowledge and inspiration about CLT and its implementation for many language teachers. Yet, these programs had not lived up to their expectations. Shima, one language teacher complains about the in-service courses she had taken:

During in service program, we were just offered a very
intensive (five-day) course which was mainly theoretical.
What we expected in this program was some hands-on
experiences of how to do real teaching. Our teacher director
simply explained some theoretical points from a power point
file. We learnt about CLT but only in theory; we did not learn
how to put it into practice.

As indicated in this excerpt, in addition to being mainly theoretical and lacking in providing some practical experiences for implementing CLT, in-service programs are usually crash undertaken during one or two weeks. Thus, it is not surprising if such intensive and mainly theoretical programs do not live up to the expectations of teachers. 


\section{Evaluation of students' learning and CLT}

In order to better recognize teachers' understanding of and expertise in assessment and evaluation, a collection of tests that they had constructed and given to their students as mid-term and final exams was analyzed. Contrary to the priority that had been assigned to the four skills by the new English curriculum, in which oral/aural skills were primary and reading and writing were secondary, the exams had reversed this order by focusing mainly on writing and reading instead of speaking and listening as if assessment and evaluation are limited only to writing and reading. In fact, for many teachers especially for those with higher teaching experiences, the default assessment practices were the same traditional paper and pencil tests. One teacher director, Farideh, who is also a teacher supervisor in her city, contends:

The exam papers that came to us for evaluation, the question items were exactly similar to those of the previous textbook. Surprisingly, as if the same sample question (the old book) for the new book.

The reason for this mismatch was clearly stated by Majid, another teacher director in this way:

Evaluation is really a major drawback. Information is very scarce in this area, and the relationship between evaluation and instruction is rocky. The teachers do not have enough information (about evaluation).

Thus, teachers' unfamiliarity with the principles of communicative language assessment was a major factor hindering teachers from using appropriate testing practices for assessing their students' communicative competence. The exam and score-oriented atmosphere of Iranian students, families, and school staff was another big issue in the Iranian English education in public schools as the activity 
system in this study. Naeem, one language teacher whose students had not done well on a traditional test constructed by another language teacher complained about the principal of the school:

... But at the moment, the main criterion is the score, not the learners' progress and development, and for this same reason, I was criticized by the principal. He told me why your students have not received high scores. He even told me you have to be responsible for such low scores in educational department.

It is likely that this dominant atmosphere in schools with regard to scores and obtaining high scores is the result of the expectations of the Iranian families. Talking about parent-teacher conferences, Maryam, a teacher director says:

The parents are only content with (high) scores. Our education system acts in such a way that if the student is put under pressure, he/she would ultimately say that I would pass (this particular course) whether you give score or not. Thus, it is not uncommon that the teacher simply gives the passing score to the student to get a higher classroom rank (compared to other teachers). The parents would ask only about their children's scores instead of thanking (the teacher) that their children have learned speaking.

Therefore, one of the most interfering barriers to the full implementation of CLT as envisioned by the new curriculum is related to assessment and evaluation of students' learning. Assessment as the other side of the instruction coin should work in tandem with teaching so that the designed outcome of the new curriculum is achieved. However, unfortunately, neither language teachers have adequate knowledge in this regard, nor do other stakeholders support language teachers to make use of more communicative tests. 


\section{Secondary and quaternary contradictions}

A number of secondary contradictions occurred between various components of the instructional activity system. The most noticeable secondary contradictions occurred between (1) subject and tool, (2) subject and object, (3) subject and rule, (4) subject and community, (5) artifact and rule, (6) artifact and object, (7) artifact and community, (8) community and division of labor, and finally (9) community and rule. These secondary contradictions are of particular importance in the activity system since it is only through the resolution of these contradictions that the activity system can be transformed into a new state as desired.

The first secondary contradiction occurred between Iranian language teachers as the subjects of the activity system and the new teaching package which is based on communicative language teaching. That is, instead of adopting communicative activities in their instruction and following the steps recommended by the new English package for teaching the content of each lesson, the subjects of this activity system fell back on traditional methods and techniques to which they had been accustomed during their prior teaching as well as learning experiences. This secondary contradiction simultaneously revealed another secondary contradiction between language teachers (subject) and the object of the instructional activity system which involves helping the students develop oral communicative proficiency. Another secondary contradiction emerged between language teachers (subjects) and the community (teacher directors). Most teachers demonstrated great persistence with regard to teaching the alphabet within the first few weeks in spite of the fact they were strongly recommended by teacher directors during in-service programs that the alphabet letters should be taught as explained in the Teachers Guide during the academic year. In case of many language teachers, this contradiction was not also resolved as intended by the new English curriculum in a sense that teachers could not help teaching the alphabet in the first few weeks.

The fourth secondary contradiction emerged between language teachers (subjects) and optimal use of English and Persian (tool). Despite their awareness of the importance of the use of English (tool) in the classroom, and despite the 
emphasis given to English as the medium of instruction by teacher directors, language teachers made extensive and liberal use of the native language resulting in another secondary contradiction between the subjects and the rule that language teachers should make optimal use of English. Another secondary contradiction occurred between the teachers (subjects) and the community with regard to the students' active participation in communicative activities. The teachers sometimes tried to get students (community) involved in communicative activities while the students did not show any interest. As a result, teachers fell back on the writing and reading activities of the workbook and spent much of class hour working on activities of this book. One reason for lack of interest in communicative activities was given by some students who stated that their participation in oral communicative activities did not help them score well on the exams that mainly aimed at assessing reading and writing skills. Accordingly, another secondary contradiction surfaces between the communicative activities (tool) and the students, their parents and school staff (community) since the latter groups did not consider oral communicative activities as important for students' final exams and grades. As such, if exams, scores, and obtaining high scores on the exams are viewed as implicit rule in this instructional activity system, a major secondary contradiction surfaces between this rule (exam-oriented culture) and language teachers (subjects) who might have intended to make optimal use of communicative activities but did not because their activities were overshadowed by this rule. Simultaneously, a similar secondary contradiction emerged between this implicit rule and communicative activities incorporated in the new textbook (artifact). As mentioned earlier, institutional constraints and issues related to classroom management prevented some teachers from conducting some communicative activities in the classroom leading to two more secondary contradictions: the first occurred between the students who got noisy when involved in communicative activities (community) on the one hand, and careful and centralized management of the classroom by the teacher (rule) on the other hand. This contradiction simultaneously reveals another secondary contradiction between the students (community) and division of labor of this instructional 
activity system in that the students were not allowed or did not want to take active role during classroom activities. Ultimately, another secondary contradiction simultaneously emerged between this rule and communicative activities (artifact).

In the present study, quaternary contradictions emerged between teachertraining in-service programs which had been planned by the Ministry of Education, and the current instructional activity system. The contradiction appeared since the subjects of the latter activity system did not see the content of the neighbor activity as helpful for their instructional program. That is, the courses offered during inservice programs were too theoretical to provide them with some hands-on experiences. Most language teachers complained that teacher directors usually delivered some lectures about CLT, assessment, and classroom management. More specifically, language teachers noted that they needed to be exposed to some communicative activities and the way they could have been implemented in the classroom because they had neither learning experiences nor teaching experiences based on communicative activities. Moreover, these courses were too short and intense running only one or two days (6 hours a day) in September and two or three days in October or November. Many language teachers could not afford to attend in-service classes held during September since they were on summer holidays; and because attendance was not mandatory. Although the administrative problems associated with in-service programs do not constitute quaternary contradiction in the real sense of the word, they do indicate that the neighbor activity system of teacher-training in-service program, which is the only governmental system in charge of teachers' professional development, did not function as effectively as expected. This is an issue particularly in our country which has a centralized education system. In such centralized educational systems, the role of the neighboring activity systems becomes essential in professional development of language teachers since they do not have any role in developing the new curriculum. Thus, in such top-down curriculum reform movement, the neighboring activity which is in charge of producing subjects for the central activity system should be able to and continue to function as flawlessly as possible. For example, 
attendance should be mandatory for all language teachers, there should be continuous opportunities for teacher professional development in line with the new curriculum, and there should be an expert body responsible for continuous observation and evaluation of teachers' work in each area.

As a way to depict secondary contradictions that emerged between various components of the current activity system and how these contradictions are related to quaternary contradictions, the following model (see Figure below) is suggested. According to this model, there were serious clashes between different components of the current activity due to the introduction of a novel factor (CLT-based curriculum). Since subject-producing activity systems such as teacher colleges and teaching training programs are responsible for producing subjects of the activity system (language teachers), and since the subjects play the most important role in resolving the secondary contradictions, it seems necessary to depict the relationship between quaternary and secondary contradictions.
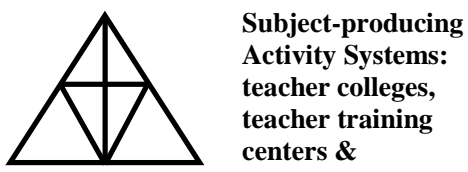

Tools: New English textbooks, lesson plans, L1/L2, exams, authentic materials, communicative activities, translation, repetition,
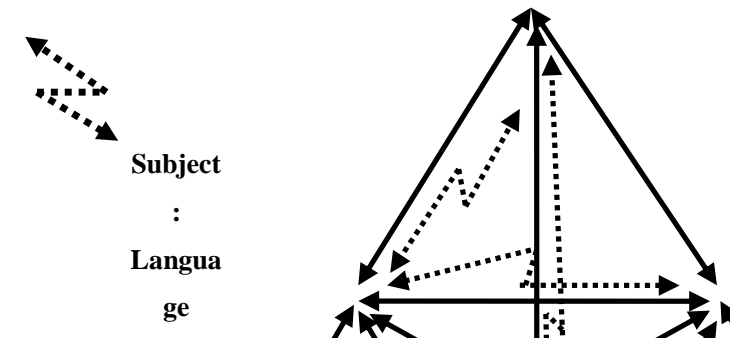

Object:

Developing communicative competence based on the communicative activities of the new textbook,

Langua

ge obtaining high

Outcome:

Upward but slow climb to the new curriculum's goal (developing communicati ve competence), students' norms (students' limited participation and L2 use), classroom management, covering textbook for exams

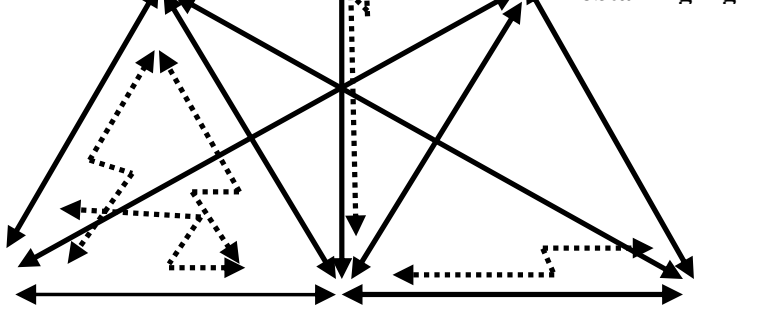

Division of Labor: teachers

Community: are in full charge of the

Language teachers, teacher directors, students, school staff, parents classroom activities, students are merely passive recipients 


\section{Figure 2}

The proposed model presenting two levels of inner-contradictions in Iranian language teachers' instruction in grades seven and eight. The dotted zigzag lines indicate secondary contradictions while the single dotted zigzag line between the central activity system (big triangle) and the subject-producing activity system (small triangle) indicates quaternary contradictions.

\section{Discussion}

The data gathered in this study yielded several significant findings especially with regard to the secondary contradictions that emerged in the Iranian English education in junior high schools as the activity system in this study. The most noticeable contradiction appeared between the Ministry of Education's introduction of CLT-based curriculum and language teachers' perceptions as well as implementation of it at the local level. Despite their general approval of the new curriculum aiming to develop communicative competence, language teachers could not fully implement the new curriculum due to the set of secondary contradictions that they experienced. More specifically, the new curriculum highlighted the development of communicative competence through various communicative activities, learner-centered instruction, optimal use of English, and due attention to all components of communicative competence. Yet, language teachers' teacherfronted instruction with excessive use of traditional methods like translation and mechanical drills prevented them from complying with the new curriculum. In addition to the existence of a number of contextual constraints, teachers' insufficient knowledge of conversational English and CLT principles constituted two major obstacles. Given the findings of the current study, the effect of such a top-down curriculum imposed by the Ministry of Education at the local level need to be further discussed.

This pattern of result (teachers' use of traditional methods) can be interpreted in terms of Vygotsky's (1963) belief about the formation of "true concepts" or 
what is considered to be the basis for expertise in a particular domain (Johnson, 2009). According to Johnson (2009), true concepts develop when everyday concepts (e.g. some aspects of traditional teaching methods like translation, mechanical drills, and traditional tests) and scientific concepts (principles of CLT) inform each other simultaneously. Given the findings of this study, it seems that teachers' everyday concepts have had a powerful influence on their instruction. Having been enculterated into normative ways of being an L2 teacher, Iranian language teachers could not successfully build on their everyday concepts in order to truly understand the scientific concepts of the new curriculum (Lantolf \& Johnson, 2007). Therefore, it was difficult if not impossible for them to reconceptualize and reconstruct their previous ways of teaching English (Johnson, 2009). Other studies conducted by Ahn (2009) and Li (1998) lend support to this finding. Ahn (2009), for example, claims that student teachers in his study fell back on some aspects of traditional teaching methods as soon as they confronted a problem since they had not interwoven their everyday and scientific concepts.

The continued and rather frequent use of some aspects of traditional teaching practices by language teachers can be interpreted in terms of teacher idenity. According to Miller (2009), "..identity is a way of doing things [which] is affected by what is legitimated by others in any social context" (P. 173). In the present study, the community members as one component of the current activity system included students, teacher directors, parents, and school staff. As indicated earlier, Iranian studnts did not take an active role during classroom interaction and preferred to use their mother tongue when engaged in pair work and group work activities. Besides, according to language teachers, teacher directors ran in-service programs in theoretical way by delivering lectures on the priciples of CLT. Moreover, the expectations of Iranian families and school staff regarding students' achievment of high scores led some teachers to draw on some instructional practices that would ensure higher scores. This view of identity implies that identity is the product of various resources which might be in conflict with each other. As indicated above, there were a number of dissonances and tensions bewteen various resources constructing Iranian teachers' identities. From an 
activity theory perspective, these tesniosns surface as secondary contradictions between the subjects of the activity system and other members of the community.

According to Fullan (1996) and Wang (2006), teachers' professional development is a strong predictor of the successful implementation of a new curriculum. Nonetheless, Iranian language teachers mentioned that they did not have the required external support especially with regard to professional development. An examination of the nature of in-service courses, teachers' meetings, and the type of supervision they experienced indicated that they were not effective from the teachers' perspective. According to Markee (1994), successful implementation of a curriculum is dependent on various factors including the new materials, methodological skills, and pedagogical values. Language teachers believed that they did not have the external support to develop their methodological and pedagogical knowledge. This is supported by findings of a study conducted by Wang (2006) who believed that lack of opportunities for professional development was the main cause of unsuccessful implementation. Moreover, a study of student teachers' practicum experiences conducted by Ahn (2009) revealed some evidence supporting the idea that teacher direcors as middle-level managers could not successfully prepare language teachers with the required skills and resources to implement the new curriculum. In the present study, teacher directors' mentoring was not consistent with the principles of CLT. For example, many language teachers complained about the teacher-fronted and theoretical nature of in-service courses. This finding has also been supported in some other studies (Lee, 2007; Richards \& Crooks, 1998).

Similar to the studies conducted by Kim (2008) and Ahn (2009), the present study also found that contextual constraints such as time pressure, large class size, problems associated with the new package, and the use of noncommunicative tests inhibited language teachers from fully and successfully implementing the new curriculum. The evaluation of students' learning was a powerful influence on language teachers' instruction and students' learning. This negative influence is driven by two sources: first, the extensive use of traditional 
paper-and-pencil tests assessing separate language components like vocabulary and grammar with a focus on reading and writing; second, considerable importance attached to obtaining high scores by different stakeholders including students themselves, their parents, and school staff. The results of this facet of the study are in line with those obtained by Ahn (2009), Namaghi (2006), and Dahmardeh (2009). The use of traditional tests which was encouraged either by language teachers' concern for ensuring students' learning of individual components of language, or their unfamiliarity with and lack of expertise to design and use communicative tests drew their instructional practices towards traditional methods of teaching. Accordingly, Iranian language teachers have tended to adopt what Namaghi (2006) called "instrumental teaching" (P. 100) in which students' learning is sacrificed for their scoring well.

Analyzing the emerging themes of English education in Iranian secondary school within an activity theory framework revealed various types of contradictions. Such an analysis makes it possible to understand why certain aspects of the new curriculum were or were not enacted by language teachers. More specifically, each layer of contradictions contains useful and obvious clues about language teachers' failure (or success thereof) to the full implementation of the new curriculum. From an activity theory perspective, the successful implementation of the new curriculum is possible only when various contradictions are successfully resolved. Until then, developing communicative competence which is the main goal of the new curriculum will not be fulfilled.

\section{Conclusion}

From an activity theory perspective (Engestrom, 1987, 1993), the most frequent and important type of contradiction that language teachers and the students might encounter is secondary contradictions since it is this type of contradiction that triggers substantial qualitative change in human activity systems. However, these changes in turn are dependent on the successful resolution of those contradictions. To resolve the secondary contradictions successfully, language teachers need to reflectively appropriate elements of the new curriculum (Cole \& Engestrom, 1995). 
Iranian language teachers' failure in successfully overcoming the secondary contradictions did not allow them to fully adapt their instructional practices to the goals and norms of the new curriculum. It is evident that successful resolution of these contradictions cannot be achieved only by language teachers who constitute only one component of the current activity system. Though language teachers as the subjects of the current activity system (English education in the Iranian public schools) play the leading role in overcoming the secondary contradictions, the influential role of the community in which language teachers work should not be overlooked since it is the community and its dominant values that determine the rules as well as the division of labor in the activity system. Given the dynamic interplay among various components of any human activity system, it is recommended that curriculum developers think of effective ways and measures to help language teachers successfully overcome the secondary contradictions so that they can successfully adapt their instruction to the new curriculum.

From an activity theory perspective, the identification and resolution of various types of contradictions within an activity system is the ultimate purpose of the research. As such, the proposal of some procedures and suggestions with regard to successful or at least partial resolution of these contradictions can constitute the implications of an activity-theory based research.

Quaternary contradictions as the clashes between a central activity system (English Education) and neighbor activity systems such as Ministry of Education, Universities, and teacher-training programs should be dealt with since the latter activity systems prepare the workforce or the subjects of the former activity system. To be more specific, the kind of education that is offered by teacher colleges and state-run universities should provide the would-be language teachers with more practical and hands-on teaching and learning experiences. That is, providing a set of theory-based courses about different methods of teaching or theories of second language acquisition would be hardly enough to prepare student teachers for tackling the unpredictable situations that might arise in a CLT-based language classroom. Indeed, an initial yet probably costly investment in neighbor 
activity systems such as universities, teacher colleges, and teacher-training programs through which quaternary contradictions are taken care of can in the long run help remove or at least reduce the number of secondary contradictions in a more effective and permanent way.

One of the most fundamental requirement of a CLT classroom is that language teachers enjoy a fairly high proficiency in oral/aural skills; something that most Iranian language teachers are lacking. Therefore, language teachers as the ultimate implementers of the new English curriculum are recommended to improve their knowledge of English language including oral/aural skills, pedagogical knowledge, and other types of knowledge that constitute the knowledge base of an effective language teacher. Language teachers can improve their speaking ability by holding some free discussion classes among themselves, whereas they can improve their pedagogical knowledge by holding some fruitful meetings in which they can share their teaching experiences, the problems that they may face while teaching the new textbooks, and ways to overcome them.

In addition to providing the required equipments at home for their children, students' parents can facilitate their children's language learning by changing their expectations of language teachers, language classrooms, and also their children's performance with the new communicative-based curriculum. As mentioned before, many teachers make use of traditional forms of assessment and homework only on families' urgent demand. In fact, creating a communicative classroom is not possible without families' cooperation. As such, students' parents should be informed about and convinced of the enormous demands of the new English curriculum that might be in contrast to those of the traditional methods. To achieve this aim, the principals of the schools and other authorities in local educational departments are recommended to hold regular meetings between language teachers and students' parents about the new English curriculum. 


\section{Acknowledgment}

The authors are grateful to the anonymous reviewer(s) and the editor of IJAL for their insightful comments on an earlier version of this paper.

\section{Note on Contributors:}

Seyyed Ayatollah Razmjoo is an associate professor of TEFL at Shiraz University, Shiraz, Iran. He has published and presented papers both nationally and internationally. His research interests are Teaching methodology, Research Methods, and Language Testing. His email address is: arazmjoo@rose.shirazu.ac.ir

Elyas Barabadi is a PhD candidate of TEFL at Shiraz University. Since 2013, he has been one of teacher directors of the Iranian Ministry of Education in Khorasane Razavi. He did his MA degree in TEFL at Ferdowsi University of Mashhad. His research interests are: Psychology and Sociology of language education, and second language teacher education. His email address is: elyas.ba1364@gmail.com

\section{References}

Alavi Moghaddam, S. B. (2013). Interview with the authors of the textbook. Retrieved from http://eng-dept.talif.sch.ir/index.php?page_id=114.

Ahn, K. (2009). Learning to teach within the curricular reform context: a sociocultural perspective on english student teachers'practicum experience in south korea (Unpublished Ph.D. dissertation). The Pennsylvania State University, University Park, PA.

Ary, D., Jacobs, L. C., \& Sorensen, C. (2010). Introduction to research in education $\left(8^{\text {th }}\right.$ Ed.). New York, NY: Wadsworth.

Calderhead, J. (2001). International experience of teaching reform. In V. Richards (Ed.), Handbook of research on teaching (4th ed.) (pp. 777-802). Washington D.C.: American Educational Research Association. 
Carless, D. R. (2001). A case study of curriculum implementation in Hong Kong. In D.R. Hall, \& A. Hewings (Eds.). Innovation in English Language Teaching (pp.263-274). New York, NY: Routledge.

Choi, S. (2000). Teachers' beliefs about communicative language teaching and their classroom teaching practices. English Teaching, 55(4), 3-32.

Cole, M., \& Engeström, Y. (1995). A commentary on mind, culture, person: Elements in a cultural psychology.(Lucariello, J.), Rev. Human Development, 38, $19-24$.

Cooper, R. L. (1989). Language planning and social change. Cambridge, UK: Cambridge University Press.

Craft, A. (2000), Creativity across the primary curriculum. London: Routledge.

Dahmardeh, M. (2009). English language teaching in Iran and communicative language teaching (Unpublished doctoral dissertation), The University of Warwick, Institute of Education.

Engeström, Y. (1987). Learning by expanding: an activity-theoretical approach to developmental research. Helsinki: Orienta-Konsultit. Retrieved September, 2002 from http://communication.ucsd.edu/MCA/Paper/Engestrom/expanding.

Engeström, Y. (1993). Developmental studies of work as a testbench of activity theory: The case of primary care medical practice. In S. Chaiklin, \& J. Lave (Eds.). Understanding practice (pp. 64-103). New York, NY: Cambridge University Press.

Engeström, Y. (1999). Communication, discourse, and activity. The Communication Review, 31(1-2), 165-185.

Fullan, M (1996). Professional culture and educational change. School Psychology Review, 25(4), 497-500. 
Fullan, M. (1998). Education reform: are we on the right track? Education Canada, 38 (3), $1-7$.

Fullan, M. (2000). The return of large-scale reform. Journal of Educational Change, 1(1), 5-27.

Harrison, I. (1996). Look who's talking now: listening to voices in curriculum renewal. In K. M. Bailey, \& D. Nunan (Eds.). Voices from the language classroom, (pp. 283-303). New York, NY: Cambridge University Press.

Johnson, K. E. (2009). Second language teacher education: A sociocultural perspective. Routledge: NY.

Karavas-Doukas, K. (1995). Teacher identified factors affecting the implementation of an EFL innovation in Greek public secondary schools. Language, Culture, and Curriculum, 8 (1), 53-68.

Kim, S. (2002). Teachers' perceptions about teaching English through English. English Teaching, 57(1), 131-148.

Kim, E.-J. (2008). In the midst of curricular reform: An activity theory analysis of teachers' and students' experiences in South Korea (Unpublished Ph.D. dissertation). The Pennsylvania State University, University Park, PA.

Larsen-Freeman, D. (1983). Second language acquisition: Getting the whole picture. In K. M. Bailey, M. Long, \& S. Peck (Eds.), Second language acquisition studies (pp. 3-22). Rowley, MA: Newbury House.

Lantolf, J. P. (2000). Introducing sociocultural theory. In J. P. Lantolf (Ed.). Sociocultural theory and second language learning (pp. 1-26). Oxford, UK:

Oxford University Press. 
Lantolf, J. P., \& Johnson, K. E. (2007). Extending Firth and Wagner's (1997) ontological perspective to L2 classroom praxis and teacher education. The Modern Language Journal, 91(1), 877-892.

Lee, S. (2007). Preservice EFL teachers' perceptions of their student teaching experiences. English Teaching, 62(4), 355-371.

Leont'ev, A. N. (1981). The problem of activity in psychology. In J. Wertsch (Ed.). The concept of activity in Soviet psychology (pp. 37-71). Armonk, NY: M.E. Sharpe, Inc.

Li, D. (1998). "It's always more than difficult than you plan and imagine": Teachers' perceived difficulties in introducing the communicative approach in South Korea. TESOL Quarterly, 32(4), 677-703.

Lincoln, Y., \& Guba, E.G. (1985). Naturalistic inquiry. Beverly Hills: Sage.

Lortie, D. (2002). Schoolteacher: a sociological study (2nd ed.). Chicago, IL: University of Chicago Press.

Markee, N. (1994). Curricular innovation: issues and problems. Applied Language Learning, 5(2), 1-30.

Markee, N. (1997). Managing curricular innovation. New York, NY: Cambridge University Press.

Miller, J. (2009). Teacher identity. In A. Burns \& J. C. Richards (Eds.), Second language teacher education, (pp. 172-182). Cambridge: Cambridge University Press.

Namaghi, S. A. O. (2006). Forces steering Iranian language teachers' work: A grounded theory. ReadingMatrix, 6(2), 90-105. 
Richards, J. C., \& Crookes, G. (1988). The practicum in TESOL. TESOL Quarterly, 22(1), 9-27.

Seaman, J. (2008). Adopting a grounded theory approach to cultural-historical research: conflicting methodologies or complementary methods? International Journal of Qualitative Methods, 7(1), 1-17.

Strauss, A., \& Corbin, J. (1998). Basics of qualitative research: Grounded theory procedures and techniques (2nd ed.). Newbury Park, CA: Sage.

Vygotsky, L. S. (1987). Thinking and speech. In R.W. Rieber \& A.S. Carton (Eds.), The collected works of L. S. Vygotsky, Vol. 1, Problems of general psychology (pp.39-285). New York: Plenum Press.

Wang, H. (2006). An implementation study of the English as a foreign language curriculum policies in the Chinese tertiary context (Unpublished Ph.D. dissertation). Queen's University, Kingston, Ontario, Canada. 